\title{
IoT Based Cloud Integrated Smart and Sustainable Classroom
}

\author{
Faritha Banu J, Balakrishnan M, Praveen Raju P, Naveen kumar M
}

\begin{abstract}
Now a day, every educational environment requires an evolution of classrooms from traditional model to a more active model of classrooms. The main objective of a classroom model is to spend more time on teaching and learning and less on organizing and monitoring the workflow of the classroom. This project proposes "IoT based Cloud Integrated Smart and sustainable Classroom". Smart classroom is developed to monitor and regularize the activities like assignments, projects, tutorial submission and attendance monitoring of the Students or scholar at ease in real time by the faculty, mentor or advisor. The proposed system monitors and reports whether the assignments, projects, tutorial is submitted on or before scheduled timeline, and sends the remainder notification to complete the assigned work in stipulated time. The proposed system utilizes Cloud Computing and Internet of Things, where sensors and processors are embedded in physical objects to form a network and communicate information with ease. RF identity card reader is fixed at each classroom to monitor the Students and give them alert, so that they meet the faculty or mentor for getting permission for attending the class if they failed to submit their work on time. Thus, by reducing the work of management, time for teaching and learning will be increased resulting in high performance of the classroom.
\end{abstract}

Keywords: IOT, Cloud Computing, RF identity.

\section{INTRODUCTION}

Internet of Things, essentially named as 'IoT' is a trend setting innovation which the universities are beginning to adjust into their task[1-2]. IoT is just a UI that a management of the university can incorporate into practically all the electrical/electronic gadgets to change them into a more intelligent one. This innovation is additionally favoured by a large group of enterprises for the assortment of usesincluding examination of gathered information, cloud information stockpiling,triggering an activity, remote notice and so forth [3]. Traditional classroom model requires equal time to be spent on both teaching and managing the workflow of the classroom. As a result, faculty and the management of the institution cannot make good students with great knowledge.

Manuscript received on April 02, 2020.

Revised Manuscript received on April 20, 2020.

Manuscript published on May 30, 2020.

* Correspondence Author

Faritha Banu J, Professor and Head, Department of Computer Science and Engineering at Jeppiaar Institute of Technology, Kunnam, Suguvarchatram.

Balakrishnan M, Pursuing Bachelors of degree, Computer science and Engineering, Jeppiaar Institute Of Technology, Sriperumpudur, Chennai, India

Praveen Raju P, Pursuing Bachelors of degree, Computer science and Engineering, Jeppiaar Institute Of Technology, Sriperumpudur, Chennai, India

Naveen kumar M, Pursuing Bachelors of degree, Computer science and Engineering, Jeppiaar Institute Of Technology, Sriperumpudur, Chennai, India.

(C) The Authors. Published by Blue Eyes Intelligence Engineering and Sciences Publication (BEIESP). This is an open access article under the CC BY-NC-ND license (http://creativecommons.org/licenses/by-nc$\underline{\mathrm{nd} / 4.0 /)}$
This is a less efficient methodology to get practiced. Thus, in order to achieve maximum utilization of the class hours, a new system is needed to take care of the workflow which highly reduce the time of faculty not to stick with managerial works but to increase the time of teaching and interaction with students[9].

This paper displays a technology that utilizes IoT along with cloud technology and application development platform like flutter to reduce the secondary work of mankind. This implementation let faculty to focus more on the primary work that is, teaching and to focus less on managing the workflow of the classroom.

\section{LITERATURE SURVEY}

First paperdeals "Internet of Things - based Smart Classroom Environment" the system is based on ARM Microcontroller, which is open hardware platform; the board can be further customized in the future to make it more tailored for the specific needs of smart classrooms. We can also consider manufacturing an all-in-one board with all the components integrated, so the costs will be much less and make it more affordable. The resultant will make the system one step closer to commercial applications. This smart classroom system not only offers the solution to a problem but also lays the foundation for series of future projects (such as intelligent parking system, dynamic ticketing system, etc.). Finally, the data collected through the system can be analysed and used for additional purposes, such as resource management, attendance checking, or tutor time tracking management. Next paper we are dealing with is "SMARTBENCHES IN CLASSROOM" this paper is based on a touch-based interface which will be stored in the cloud-based framework and can be only accessed through a security-based system using RFID [7]. These interfaces are provided in each bench in the class which makes them a smart bench. Students will interact with as notepad which helps them to take notes while listening to the class and it also help them for easy understanding and resource virtualization. New technological advancements in communication have led to a major change in teaching and learning models when we see based on education [8]. Next paper we are dealing with is "Experiences with IoT and AI in a Smart Campus for Optimizing Classroom Usage" this paper provides 4 contributions to the implementation of IOT and AI in advancement of classroom. First contribution is about IoT sensing approaches for measuring class occupancy, and comparing them in terms of cost, accuracy, privacy, and ease of deployment/operation. Second contribution is 9 lecture halls of varying capacity across campus, collects and cleans live occupancy data spanning about 250 courses over two sessions, 
and draws insights into attendance patterns, including identification of cancelled lectures and class tests, while also releasing our data openly to the public. Third contribution is to use AI techniques for predicting classroom attendance, applying them to real data, and accurately predicting future attendance with an error as low as 0.16. final contribution is to develop an optimal allocation of classes to rooms based on predicting attendance rather than enrolment, resulting in over $10 \%$ savings in room costs with very low risk of room overflows. Next paper is "Key Technologies of Smart Campus Teaching Platform Based on 5G Network" this paper is based on the $5 \mathrm{G}$ network implementation in the campus. it is considering the business demand and performance demands which is satisfied with $5 G$ network. From the above discussed papers, we have considered some technologies like RFID, IOT \& AI based infrastructure and cloud storage system. we are implementing them on our paper as cloud storage for handling smart application through which interaction between teacher and student take place. Then, RFID, IOT and AI based infrastructure were implemented for checking the student completion of work provided to them through the application and their RFID were added to the system as per the completion of the work. If the persons RFID is in the system. Then, the student is allowed into the class.

\section{PROPOSED SYSTEM}

To provide a classroom with more interaction between students and faculty and to focus more on teaching and less on managing for the faculty the propped system is utilized. It also brings sincerity to the students on classroom activities.

\section{Methodology:}

An IOT and cloud based intelligent system will take care of the workflow which highly reduce the time of faculty to stick with managerial works and it increases the time of teaching and interaction with students. The proposed system includes web application development which allows faculties to post their assignments with due date. The students receive the assignments and can submit their work through the application. The system includes an IoT based RFID reader and buzzer alert system controlled by a Microcontroller. This subsystem will monitor the students and take necessary action as programmed.

This proposed system has three major development steps viz., Fabrication of Web Application, Buildingthe Alert SubSystem and Integration.

\section{Fabricating the Web Application:}

For the web application to be highly productive and to create highly customized user experiences, PHP, JavaScript, jQuery are used here to fabricate the web application. In this web application, students, administrators, faculty members are given login credentials Fig.1. Faculty members will be authorized by administrators to post assignments with due dates or any other provided option. Notifications will be sent to student's registered email ID. Students will receive the assignments through this web application and can able to submit their work. List of Student names with their ID number who submit work on time will be sent to the faculty's system. The following screenshots of the web application demonstrates the Login page, Administrator page, Faculty dashboard, Student dashboard, Assignment evaluation system in the Fig.1, 2, 3, 4 and 5respectively.

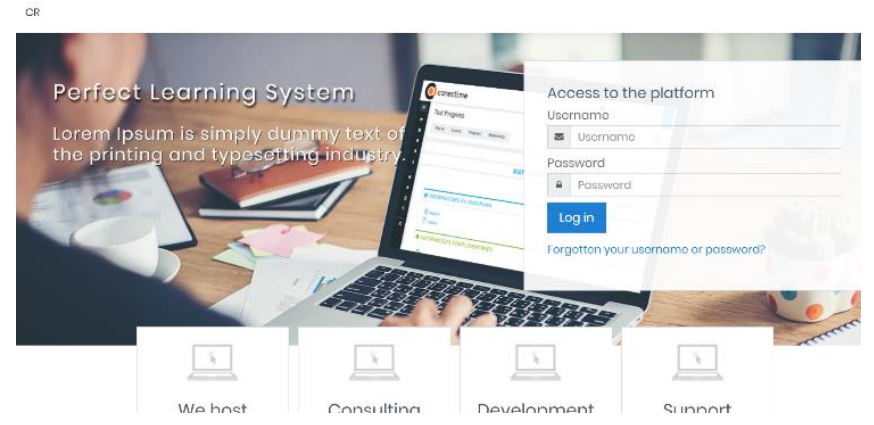

Fig.1: Login Page
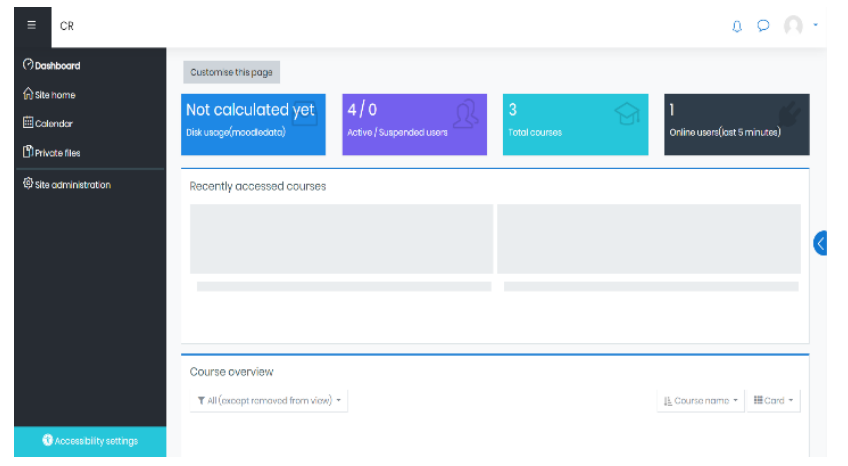

Fig.2: Admin Dashboard
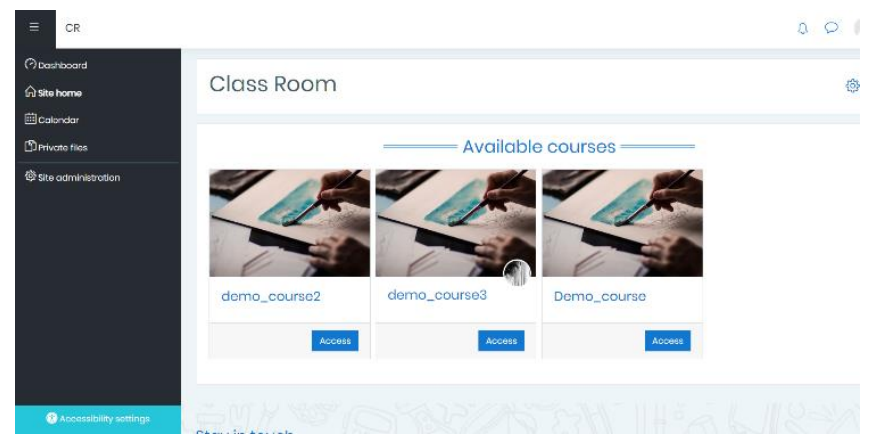

Fig.3: Faculty Dashboard
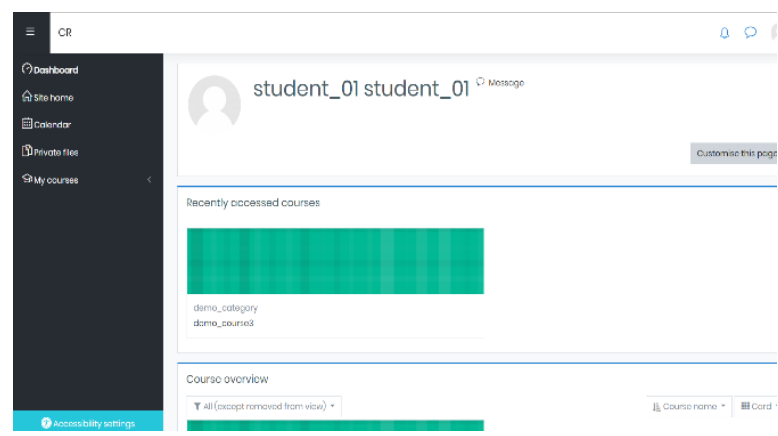

Fig.4: Student Dashboard

This web application also possesses evaluation system for the assignments submitted by the students via the web application Fig.5.

Published By:

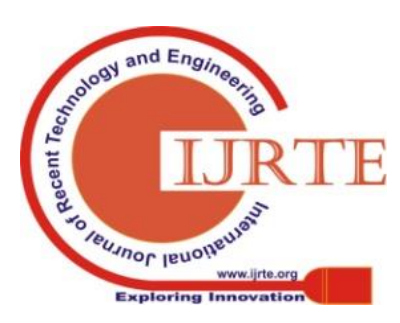




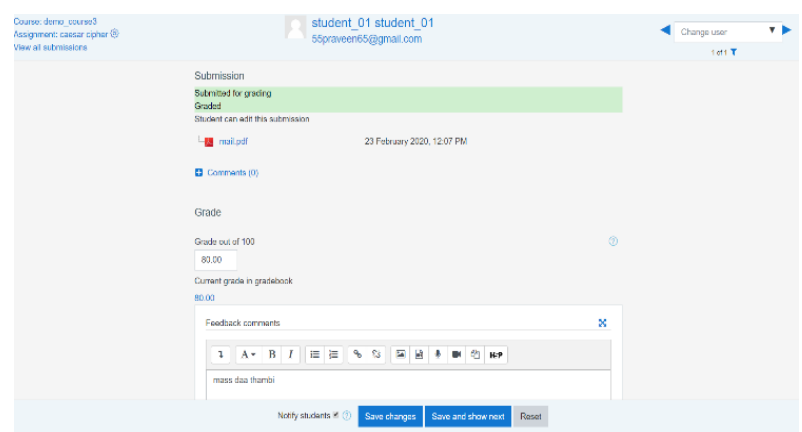

Fig.5: Evaluation System

\section{Database:}

HeidiSQLis used here for the database management. HeidiSQL(Fig.6)is a free open-source administration tool for MySQL and its forks.

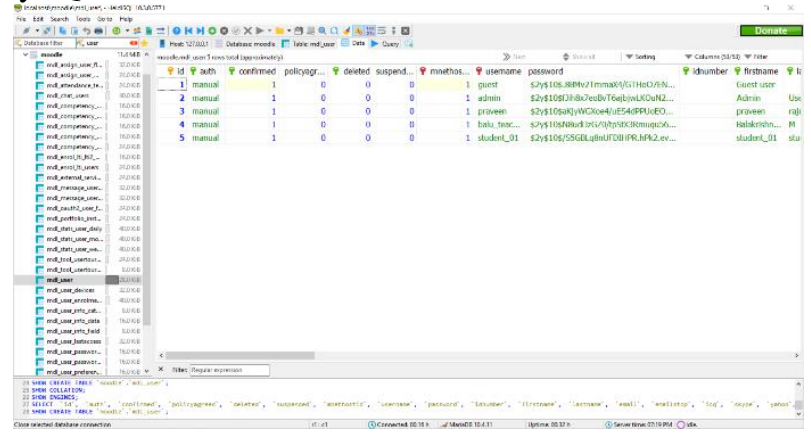

Fig.6: HeidiSQL

\section{The Alert Sub-System:}

Student ID cards are enabled with Radio frequency identification (RFIDs). RFID for each registered username will be stored in the system. A RDIF reader along with a buzzer system controlled by a microcontroller (NodeMCU Fig. 7) will be fixed in front of every classroom[4]. The RFID list corresponds to the students who submitted the assignment before due date will be transferred to the RFID reader micro system. Students who completed the work on or before the due date will only be allowed to enter the classroom. If a student tries to enter the classroom without submitting the assignment, the buzzer will alert the student to meet the mentor. Attendance for the day is based on the entry.

All information are stored in database using HeidiSQL. Thus, retrieving of the data stored is made easier.

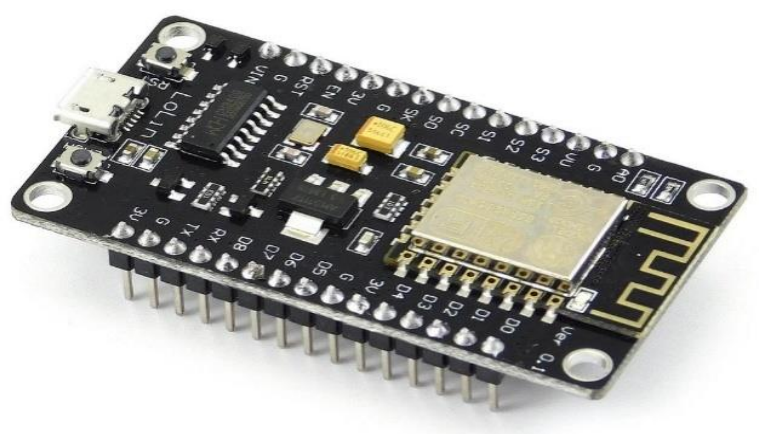

Fig.7: NodeMCU

Fig.7 shows the Microcontroller (NodeMCU) used in the scanner sub-system.

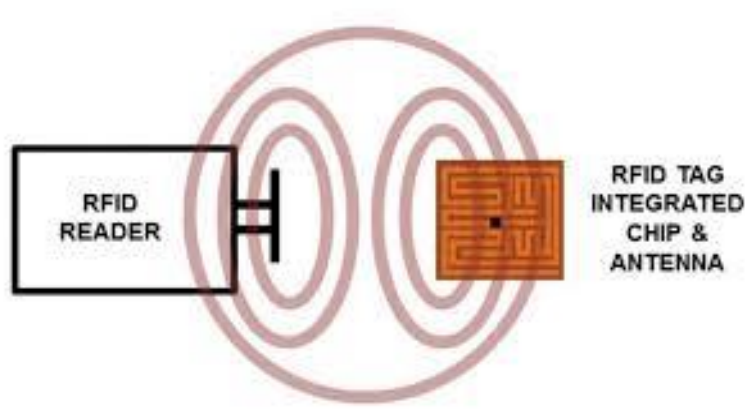

Fig.8.1: RFID Scanner System

Fig.8.1 shows the working of RFID Scanner System working.

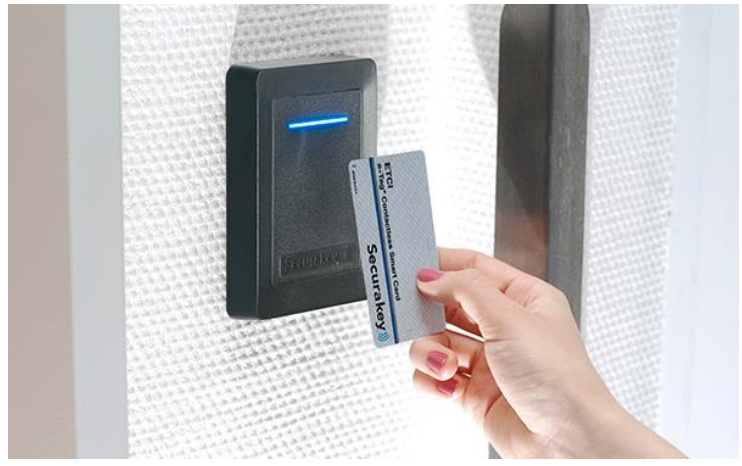

Fig.8.2: RFID Scanner System

Fig.8.2 shows the RFID Scanner System consist of fixed RFID readers at the entrance of the classroom.

Architecture of the proposed system is shown in the Fig.9.

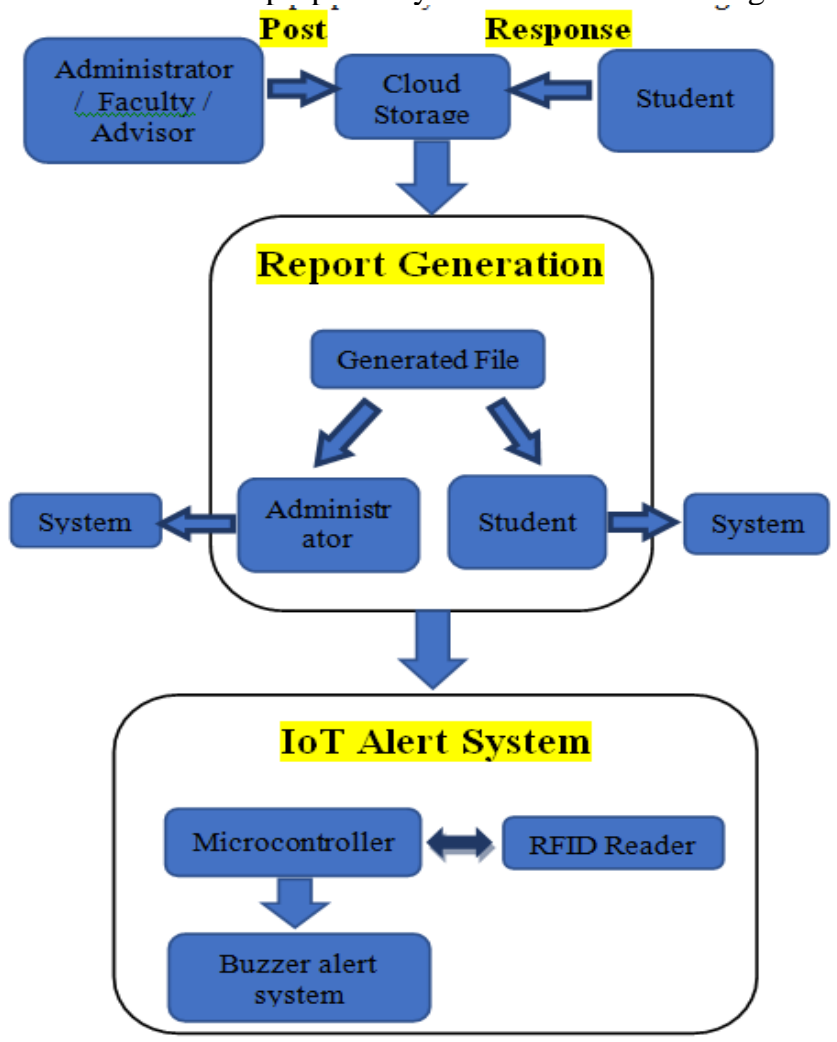

Fig. 9. The Proposed System 


\section{Technologies Used:}

The web application is developed using programming languages including PHP and JavaScript including features like, posting the assignment with due date, submitting the response through the application, sharing notes through the app, sending notifications to the students, creating the list of students who completed the work on time. The list generated by the application will be sent to administrator/mentor/advisor's system. And, to the Microcontroller [10]. A RFID reader will be fixed at each classroom controlled by a Microcontroller[5-6]. A type of microcontroller called Node MCU is used in this system

A buzzer alert system fixed will intimate the student to enter the classroom or to meet their mentors based on the assignment completion status.

The workflow of the proposed system is depicted in the Fig. 10.

\begin{tabular}{|c|}
\hline NOTIFICATION AND DATA \\
DISTRIBUTION SYSTEM \\
\hline
\end{tabular}

\begin{tabular}{|c|}
\hline MICROCONTROLLER \\
\hline RFID READER \\
\hline BUZZER ALERT SYSTEM \\
\hline
\end{tabular}

Fig.10. The Workflow Diagram

\section{RESULTS AND DISCUSSION}

The developed has two components mainly, 1.web application and 2. Alert subsystem. The web application generates a .CSV file containing the name, email, start time, completed time, date Grade marks, overall class average etc as shown in the fig.11. The alert sub-system takes these inputs and generates the alarm whenever the student enters the class without the assignment submission. Based on these results the student's attendance for the day is updated. Fig.11 shows the format of the CSV file generated.

\begin{tabular}{|c|c|c|c|c|c|}
\hline Surname & First nameEmail add State & Started or Complete & aTime tak & e Grade & $0.0 .1 / 10.00$ \\
\hline student__ & 0student_055praveer Finished & 23 Februa 23 Februa & 35 secs & 10.00 & 10.00 \\
\hline student__ & 0 student_055praveer In progre & 23 Februa - & - & - & - \\
\hline Overall av & verage & & & 10.00 & 10.00 \\
\hline
\end{tabular}

\section{Fig.11. CSV File Format}

\section{CONCLUSIONS}

On implementing this project, there will be an evolution in the educational environment resulting in high efficiency and effectiveness of classroom teaching methodology. This project will bring sincerity among student community to complete the work on time. Also, faculty and management can spend more time on teaching and learning instead of spending time with managing and monitoring the workflow of the classroom with the help of the proposed system.

Future work of this project includes, finding the location of classrooms and laboratory in a department block or in the entire university.Administrator and management of the institution can find the location of the student inside the university premises to verify whether student is attending the class or not.Using Robotic Process Automation (RPA), attendance registers for each period can be automated.

\section{REFERENCES}

1. Srinivas, Voore Subbarao, Pavithr. "A Survey on Internet of Things Based Smart, Digital Green And Intelligent Campus" IEEE 2018, 978-1-7281-1253-4

2. Sagar KN Vinay, S.M. Kusuma, "Home Automation Using Internet of Things" in International Research Journal of Engineering and Technology (IRJET), Bangalore, India, vol. 02, no. 03, June2015.

3. Asim Majeed, Mahmood Ali, "How Internet-of-Things (IoT) Making the University Campuses Smart?" of IEEE 2018, 978-1-5386-4649-6.

4. Ms.Margret Sharmila f, Suryaganesh P, M.Abiskek, ullas Benny (2019). "IoT Based Smart Window using sensor Dht11" Advanced Computing and Communication Systems (ICACCS), International Conference on IEEE.

5. Amir Atabekov, Marcel Starosielsky, Dan Chia-Tien Le, Jing Selena $\mathrm{He}$ (2015). "Internet of Things-Based Temperature Tracking System" of Computer Software and Applications Conference (COMPSAC), IEEE Annual International.

6. Rahul Dagar, SubhranilSom, Sunil Kumar Khatri (2018). Smart Farming - IoT in Agriculture of Inventive Research in Computing Applications (ICIRCA), International Conference on IEEE

7. Sumeet Bajaj, Shreyas Kumbhakarn, ApekshaBandekar." Smartbenches In Classroom" of International Conference on Inventive Research in Computing Applications (ICIRCA 2018) IEEE 2018, ISBN 97853864562.

8. ThanchanokSutjarittham, Hassan Habibi Gharakheili, Salil S. Kanhere, and Vijay Sivaraman. "Experiences with IoT and AI in a Smart Campus for Optimizing Classroom Usage" of IEEE INTERNET OF THINGS JOURNAL, IEEE 2018, ISSN 2327-4662.

9. Xin $\mathrm{Xu}$, Dan Li, Mengyao Sun, Shichao Yan, Shujiang $\mathrm{Yu}$, Gunasekaran Manogaran, George mastorakis. "Research on Key Technologies of Smart Campus Teaching Platform Based on 5G Network" of Special Section on Roadmap To 5g: Rising To The Challenge, IEEE February 2019, ISSN 2169-3536.

10. M. Shobana, M. Amsaveni, S. Sugapriya, "Smart LED lighting system for streetlight", The International Journal of Engineering and Science (IJES), March 2015, ISSN 2319-1813.

\section{AUTHORS PROFILE}

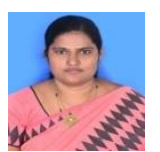

Dr.J.Faritha Banu is currently working as a Professor and Head in the Department of Computer Science and Engineering at Jeppiaar Institute of Technology, Kunnam, Suguvarchatram. Having 18 years of Teaching Experience currently. Her area of interest is networking, Compiler design, Operating System, Data structures. Life member of Indian Society for Technical Education (ISTE). E- mail: banujahir@gmail.com.

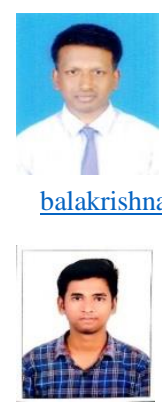

Balakrishnan $\mathbf{M}$ is currently pursuing Bachelors of degree in Computer science and Engineering in Jeppiaar Institute Of Technology, Sriperumpudur, Chennai, India. He has Participated and Presented papers in National, Internationa Conferences on Recent Trends in Bigdata Technologies. Active member in Computer Society of India. E-mail: balakrishnanm09@gmail.com.

Praveen Raju $\mathbf{P}$ is currently pursuing Bachelors of degree in Computer science and Engineering in Jeppiaar Institute of Technology, Sriperumbudur, Chennai, India. He is doing internship at MQspectrum Ltd. in the web development domain. Active member in Computer Society of India. Email: 55praveen65@gmail.com

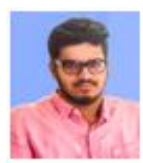

Naveen Kumar $\mathbf{M}$ is currently pursuing Bachelors of degree in Computer science and Engineering in Jeppiaar Institute of Technology, Sriperumbudur, Chennai, India. He did course in JAVA and PHP. E-mail: naveenmagesh26@gmail.com. 